\title{
Características mORFológicas y anatómicas de LAS PLÁNTULAS DE TRICHOCEREUS CANDICANS (CACTACEAE)
}

\author{
VIVIANA J. CENIZO1,2, MÓNICA B. MAZZOLA², BÁRBARA M. CORRÓ MOLAS² y \\ ALICIA G. KIN ${ }^{1}$
}

\begin{abstract}
Summary: Anatomical and morphological characteristics of Trichocereus candicans (Cactaceae) seedlings. The aim of this study was to examine the morpho-anatomical characteristics of Trichocereus candicans (Gillies ex Salm-Dyck) Britton \& Rose seedlings, a columnar cacti species widely distributed in arid and semiarid regions of Argentina. The most significant changes in seedling morphology can be observed within the first 30 days from germination. Primary root is characterized by abundant radical hairs and a definite-growth pattern. Epidermis is uniseriate with wavy cells, parallelocytic stomata and mineral inclusions (druses). Xylem is composed by wide-band tracheids, with either helical or annular thickenings. Abnormal seedlings with three cotyledons were observed. This study provides basic knowledge of the species that may be useful for further taxonomic and ecological studies.
\end{abstract}

Key words: Trichocereus candicans, morphology, anatomy, seedling, cacti.

\begin{abstract}
Resumen: El objetivo del presente trabajo fue analizar el desarrollo morfológico y las características anatómicas de las plántulas de Trichocereus candicans (Gillies ex Salm-Dyck) Britton \& Rose, una especie de cactus columnar ampliamente distribuida en regiones áridas y semiáridas de Argentina. Durante los primeros 30 días desde la germinación, se registran en las plántulas los mayores cambios morfológicos. La raíz presenta abundantes pelos radicales y un patrón de crecimiento definido. La epidermis es uniestrata con células de contorno ondulado, estomas de tipo paralelocítico e inclusiones minerales en forma de drusas. El xilema presenta traqueidas de banda ancha con paredes celulares anilladas y helicoidales. Se observaron plántulas con crecimiento anormal (tres cotiledones), lo que constituye el primer registro para $T$. candicans. Este trabajo aporta datos básicos al conocimiento de la especie que pueden ser de gran utilidad para estudios taxonómicos y ecológicos.
\end{abstract}

Palabras clave: Trichocereus candicans, morfología, anatomía, plántula, cactáceas.

\section{INTRODUCCIÓN}

Los atributos anatómicos, morfológicos y fisiológicos presentes en las cactáceas les confieren la capacidad para sobrevivir en las condiciones ambientales extremas típicas de los ambientes áridos y semiáridos donde habitan (Gibson \& Nobel, 1986). La mayoría de los caracteres morfológicos son empleados frecuentemente con propósitos

1 Facultad de Agronomía, Universidad Nacional de La Pampa, CC 300, 6300, Santa Rosa, La Pampa, Argentina.

2 Facultad de Ciencias Exactas y Naturales, Universidad Nacional de La Pampa, Uruguay 151, 6300, Santa Rosa, La Pampa, Argentina.

E-mail: vivianajorgelina@hotmail.com; kin@agro.unlpam. edu.ar sistemáticos $\mathrm{y}$, en forma adicional, los anatómicos también contribuyen a la solución de problemas taxonómicos (Herrera-Cárdenas et al., 2000). Para la familia Cactaceae se han realizado descripciones morfológicas y anatómicas tanto en plántulas (Mauseth, 1978; Dubrovsky, 1997; Dubrovsky \& Gómez-Lomeli, 2003; Loza-Cornejo et al., 2003; Ayala-Cordero et al., 2006; Loza-Cornejo \& Terrazas, 2011) como en individuos adultos (Boke, 1980; Mauseth, 1982a, b, 2006; Eggli, 1984; Gibson \& Nobel, 1986; Herrera-Cárdenas et al., 2000; LozaCornejo \& Terrazas, 2003; Terrazas et al., 2005; García Aguilar et al., 2009). Sin embargo, ha sido poco estudiado el proceso de diferenciación de las distintas estructuras desde la germinación y durante las primeras semanas de vida de las cactáceas. Este tipo de conocimiento adquiere relevancia al 
tratar de entender el rol ecológico de los diferentes caracteres durante el establecimiento de la plántula. Por ejemplo, algunos estudios sugieren que las características del desarrollo temprano del sistema radical estarían directamente relacionadas con el proceso de absorción rápida de agua y nutrientes que favorece la supervivencia de las plántulas (Dubrovsky, 1997; Dubrovsky \& Gómez-Lomeli, 2003; Loza-Cornejo et al., 2003).

El presente estudio tiene como objetivo describir la morfología y las características anatómicas de las plántulas de Trichocereus candicans (Gillies ex Salm-Dyck) Britton \& Rose en las primeras etapas de su ciclo de vida. Esta especie presenta la distribución más austral dentro del género Trichocereus, un taxón típicamente sudamericano (Kiesling, 1978). Las plantas adultas poseen uno a varios tallos columnares, de color verde pálido de unos $60 \mathrm{~cm}$ de altura y de 13 a $16 \mathrm{~cm}$ de diámetro, con espinas largas en areolas grandes y lanosas. Crecen en ambientes áridos y semiáridos del sur de La Rioja, San Juan, San Luis, Córdoba, Mendoza, sierras bajas de La Pampa, sur de Buenos Aires y norte de Rio Negro (Kiesling, 1978). Este trabajo describe e ilustra aspectos importantes de la biología de esta especie.

\section{Materiales y Métodos}

Para la descripción de las características morfológicas y anatómicas se obtuvieron plántulas de $T$. candicans por germinación. Para ello, se prepararon 15 cajas de Petri previamente esterilizadas, con una fina capa de algodón y papel de filtro embebidos con agua destilada. Sobre el papel humedecido se colocaron las semillas $(n=$ 25) previamente desinfectadas superficialmente por inmersión en una solución de hipoclorito de sodio al $10 \%(1: 5 \mathrm{v} / \mathrm{v})$ durante 2 minutos y luego enjuagadas con agua destilada. La germinación se llevó a cabo en cámara de germinación a $25^{\circ} \mathrm{C}$ con fotoperíodo de 12 hs luz y 12 hs oscuridad. La semilla se consideró germinada cuando se observó la aparición de la radícula. Se obtuvieron 300 plántulas que fueron mantenidas en cajas de Petri bajo las mismas condiciones de siembra en la cámara de germinación durante 12 semanas. Para la descripción de los cambios morfológicos se seleccionaron, al azar, 35 plántulas que fueron observadas diariamente desde la germinación hasta los 30 días de vida. El material fue examinado con microscopio estereoscópico y posteriormente se realizaron las ilustraciones.

La caracterización morfométrica se realizó en tres grupos de plántulas de diferentes edades: una $(n=45)$, cuatro $(n=32)$ y seis semanas de vida ( $n$ $=35$ ). Las mismas se colocaron bajo el microscopio estereoscópico y se midieron utilizando un calibre digital según se muestra en la Fig. 1.

Para el estudio anatómico y la descripción de los tejidos se hicieron preparados temporarios de material fresco y de material fijado en FAA (alcohol
A

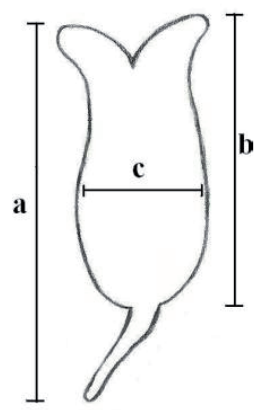

B

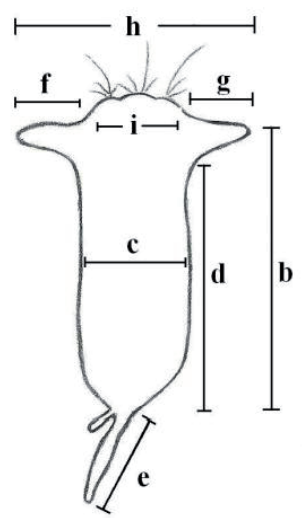

a) Longitud total

b) Longitud del eje hipocótilocotiledonar

c) Diámetro del hipocótilo

d) Longitud del hipocótilo

e) Longitud de la raíz

f) Longitud cotiledón 1

g) Longitud cotiledón 2

h) Longitud entre los extremos distales de los cotiledones

i) Diámetro del epicótilo

Fig. 1. Diagrama de las mediciones realizadas en plántulas de A: Una semana, B: Cuatro y seis semanas de vida. 
$96^{\circ}$ - agua destilada - formol - ácido acético glacial en proporción 10:7:2:1) en plántulas seleccionadas al azar, de una, cuatro y 12 semanas de vida. Para la descripción de la anatomía se hicieron cortes transversales y longitudinales a mano alzada. Para la observación paradermal de la epidermis se adaptó la técnica de raspado (D’Ambrogi de Argüeso, 1986). El material fijado en FAA se tiñó con safranina y Sudan IV. Las observaciones se realizaron bajo microscopio óptico y estereoscópico.

Una vez finalizadas las 12 semanas las plántulas fueron trasplantadas a macetas con una mezcla de grava-arena-suelo $(1: 1: 1)$ y se mantuvieron en invernáculo con dos riegos semanales para determinar el momento de reabsorción de los cotiledones y aparición de las primeras costillas.

\section{Resultados}

\section{Morfología y anatomía de las plántulas}

La semilla es pequeña $(0.4128 \pm 0.0058 \mathrm{mg})$ y el tegumento es rugoso, levemente irregular y de color negro brillante. Presenta la escama hilar u opérculo bien definida donde se encuentra el hilo y el orificio micropilar. La germinación de las semillas es epígea, iniciándose con el rompimiento de la testa en línea oblicua por debajo del opérculo seguida por la aparición de la radícula blanca, curva y corta (Fig. 2A). Desde este momento son claramente visibles los pelos radicales unicelulares, transparentes y abundantes que superan en longitud a la radícula. Estos últimos se observan en toda la superficie de la misma incluso en el extremo distal o apical. En un período de tres a seis días posteriores a la germinación se produce la emergencia y elongación del hipocótilo (Fig. 2B, C), los cotiledones (Fig. 2D) y el alargamiento de la raíz primaria.

A la semana de vida se observa el hipocótilo suculento de coloración verde clara, visiblemente diferenciado de la raíz por el color y el cuello de la misma. (Fig. 3A). Cabe destacar que en el extremo apical de la raíz no se observa cofia sino pelos radicales (Fig. 4A). El hipocótilo y los cotiledones forman un eje suculento de forma globosa a elongada, de $0.85-1.74 \mathrm{~mm}$ de diámetro y $2.49-5.73 \mathrm{~mm}$ de longitud total (Tabla 1). Los cotiledones, en número de dos, son opuestos y ligeramente separados entre sí, de modo que el eje longitudinal de los cotiledones permanece aproximadamente paralelo al eje longitudinal del hipocótilo (Fig. 3A). Los mismos son pequeños, turgentes, sésiles, glabros, cónicos a subcónicos, iguales a subiguales, con la base amplia y los ápices agudos. En su interior, se observa un parénquima clorofiliano uniforme y un haz vascular colateral. La epidermis que recubre el eje hipocótilo-cotiledones, vista en superficie, consta de células con contorno ondulado o lobulado (paredes celulares anticlinales) (Fig. 4B) y núcleos claramente visibles. Los estomas presentes en los cotiledones y el hipocótilo, son superficiales y paralelocíticos con 3-4 células anexas (Fig. 4B). El epicótilo es visible sólo microscópicamente y presenta tricomas simples, pluricelulares (3-5 células) y translúcidos (Fig. 4C).

A partir de la segunda semana de vida, la raíz principal se torna de color pardo claro y comienzan a desarrollarse pequeñas ramificaciones laterales. Al mismo tiempo, en la región apical-caulinar se hace visible macroscópicamente el epicótilo, con la aparición de los primordios de las areolas en la base de cada cotiledón, los cuales comienzan a tomar una posición perpendicular al hipocótilo (Fig. 2E, F). En cada primordio de la areola se observan 1-2 espinas hialinas, pluricelulares, largas, rectas, flexibles, puntiagudas y rodeadas de varios tricomas más cortos que las espinas (Fig. 4C, D). En el transcurso de la tercera semana las primeras areolas presentan 1-4 espinas nuevas y se distinguen los primordios de dos nuevas areolas ubicados en posición alterna con los ya existentes (Fig. 2G). Las cuatro areolas con espinas van desarrollándose en forma gradual y son claramente notorias hacia las cuatro semanas de vida (Fig. 2H, 3B). En ese momento, el hipocótilo alcanza un diámetro de 1.63-2.88 mm y la longitud desde la base del mismo hasta el extremo de los cotiledones varía entre 4.32-5.85 mm, incrementándose ambas dimensiones en aproximadamente un $60 \%$ con respecto a la primera semana de vida (Tabla 1). Este tamaño no se incrementa en los días siguientes, observándose incluso una leve reducción del tamaño de los cotiledones, del hipocótilo y de la raíz hacia la sexta semana de vida (Tabla 1).

En plántulas de 12 semanas, el hipocótilo presenta la epidermis uniestrata con cutícula delgada. En las células de la epidermis son visibles cristales agregados alrededor de un núcleo central (drusas) (Fig. 4E). Subyacente a la epidermis está el tejido parenquimático fotosintético constituido por células grandes y poliédricas, de paredes finas y con cloroplastos discoidales. En el centro hay un cordón 
Bol. Soc. Argent. Bot. 48 (3-4) 2013

A

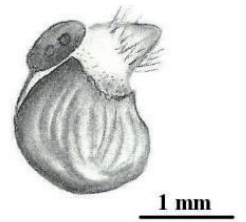

C

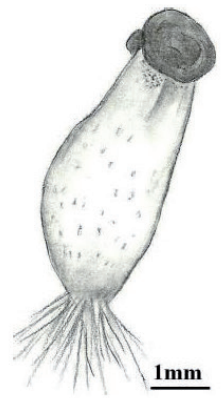

$\mathbf{E}$

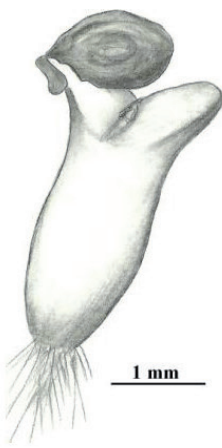

G

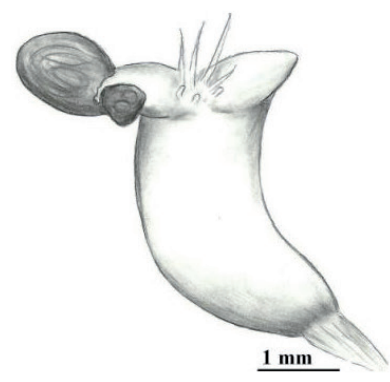

B

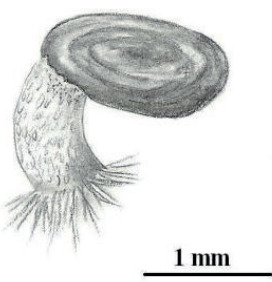

D

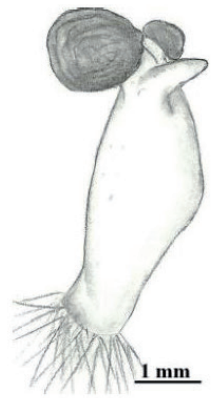

F

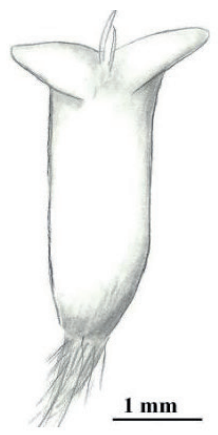

H

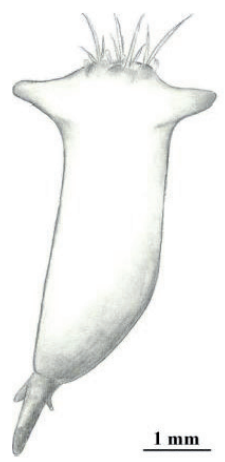

Fig. 2. Morfología de plántulas de T. candicans durante las primeras cuatro semanas de vida. A: Aparición de radícula y pelos radicales (1 día). B: Emergencia del hipocótilo (3 días). C: Elongación del hipocótilo (3-6 días). D: Cotiledón emergiendo de la testa (6 días). E: Aparición de primordios de areolas (7 días). F: Aparición de las primeras espinas (7-11 días). G: Epicótilo con tricomas y espinas (14-21 días). H: Epicótilo desarrollado con cuatro areolas, tricomas, espinas y raíz ramificada (30 días). 
Tabla 1. Dimensiones de las plántulas de $T$. candicans correspondientes a la primera, cuarta y sexta semana de edad. Los valores expresan la media \pm error estándar.

\begin{tabular}{|lccc|}
\hline \multicolumn{1}{c}{$\begin{array}{c}\text { Medida } \\
(\mathrm{mm})\end{array}$} & \multicolumn{3}{c|}{ Edad de la plántula (semanas) } \\
\hline Longitud total & $3.94 \pm 0.11$ & Cuarta & Sexta \\
Longitud eje hipocótilo-cotiledones & $3.22 \pm 0.09$ & - & - \\
Diámetro del hipocótilo & $1.32 \pm 0.03$ & $2.16 \pm 0.07$ & $4.72 \pm 0.08$ \\
Longitud del hipocótilo & - & $4.33 \pm 0.08$ & $1.83 \pm 0.03$ \\
Longitud de la raíz & - & $2.02 \pm 0.11$ & $1.04 \pm 0.09$ \\
Longitud cotiledón 1 & - & $0.60 \pm 0.02$ & $0.49 \pm 0.03$ \\
Longitud cotiledón 2 & - & $0.56 \pm 0.02$ & $0.46 \pm 0.03$ \\
Longitud entre los extremos distales de los cotiledones & - & $2.95 \pm 0.06$ & $2.96 \pm 0.06$ \\
Diámetro del epicótilo & - & $1.79 \pm 0.06$ & $2.00 \pm 0.09$ \\
\hline
\end{tabular}

vascular que se extiende desde el cuello de la raíz hasta aproximadamente un tercio del hipocótilo. En los dos tercios siguientes del hipocótilo, el cordón vascular se separa en dos haces y se distingue una región parenquimática central. Los dos haces vasculares recorren el eje hipocotilar hasta ingresar cada uno en un cotiledón. Cada haz tiene forma de arco, con el xilema en el centro y floema en cada extremo del arco. El xilema presenta traqueidas de banda ancha con engrosamientos anulares y helicoidales de la pared celular (Fig. 4F). El seguimiento de las plántulas después de las 12 semanas de vida mostró que a los 5-7 meses de edad ocurre la reducción completa de los cotiledones, mientras que las costillas características de la especie son evidentes después del año de vida.

Durante el período de estudio se observaron seis individuos con tres cotiledones equidistantes, cada uno con un primordio de areola en la base (Fig. 3C). Además, se observó una plántula con tres cotiledones dos en posición opuesta y otro en posición lateral, cada cotiledón con un primordio de areola (Fig. 3D). En ambos casos se realizaron cortes histológicos a mano alzada que evidenciaron la presencia de un haz vascular en cada cotiledón.

\section{Discusión Y CONCLUSIONES}

Durante el proceso de germinación, el tegumento seminal de $T$. candicans se abre debajo de la escama hilar, es decir, forma un opérculo y una zona de grietas laterales predeterminadas. Este tipo de germinación denominada opercular, es el más frecuente en las Cactáceas nativas de América del Sur, y permite que las semillas germinen rápidamente cuando las condiciones son favorables (Bregman \& Bouman, 1983). La plántula de T. candicans presenta la morfología típica de Cactaceae, con radícula delgada, hipocótilo suculento con dos cotiledones pequeños y carnosos (Gibson \& Nobel, 1986).

El crecimiento de la plántula es muy lento, sin embargo el desarrollo de la raíz desde la germinación es muy rápido. Aún antes de la emergencia del hipocótilo, ya es posible observar gran cantidad de pelos radicales largos y abundantes sobre toda la radícula. Esta característica aumentaría enormemente la superficie radical, permitiendo la rápida absorción de grandes cantidades de agua desde la germinación y favoreciendo el almacenamiento de la misma en el hipocótilo (Dubrovsky, 1997; Dubrovsky \& Gómez-Lomeli, 2003; Loza-Cornejo et al., 2003). La ausencia de cofia y la pronta aparición de las ramificaciones laterales durante las primeras semanas de vida, junto al cese temprano del crecimiento en longitud del eje principal de la raíz, sugieren que dicho eje tiene un crecimiento definido según el patrón descripto por Dubrovsky (1997). Dicho autor describe para Stenocereus gummosus (Engelm.) A. Gibson \& K.E. Horak, Ferocactus peninsulae (F.A.C. Weber) Britton \& Rose y Pachycereus pringlei (S. Watson) Britton \& Rose, la forma en que el agotamiento temprano del meristema apical de la raíz provoca la desaparición de la cofia 
Bol. Soc. Argent. Bot. 48 (3-4) 2013

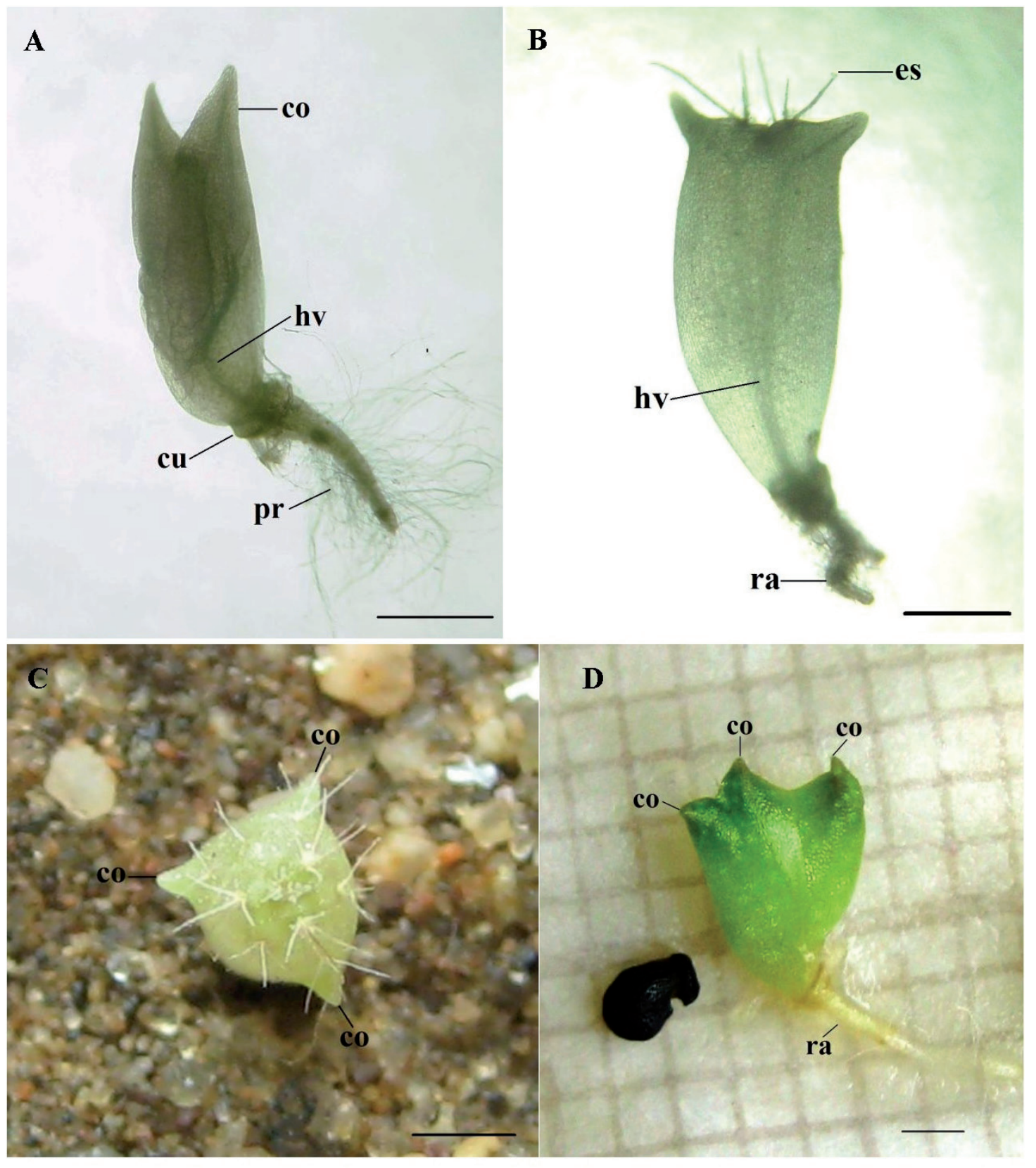

Fig. 3. Vista general de plántulas de T. candicans, A: Una semana desde la germinación. B: Cuatro semanas desde la germinación. C: Plántula con tres cotiledones equidistantes (120 días). D: Plántula con tres cotiledones, dos en posición opuesta y uno lateral (45 días). Referencias, co: cotiledón, cu: cuello de la raíz, es: espina, hv: haces vasculares, pr: pelos radicales, ra: raíz. Escala: $1 \mathrm{~mm}$.

(decapitación fisiológica de la raíz) e induce la iniciación de las raíces laterales (Dubrovsky, 1997; Dubrovsky \& Gómez-Lomeli, 2003). El patrón de crecimiento determinado de la raíz primaria es considerado inusual en las Angiospermas y ha sido observado solamente en un número reducido de especies de las tribus Pachycereeae y Cacteae (Dubrovsky \& North, 2002). 


\section{J. Cenizo et al. - Morfo-anatomía de Trichocereus candicans}
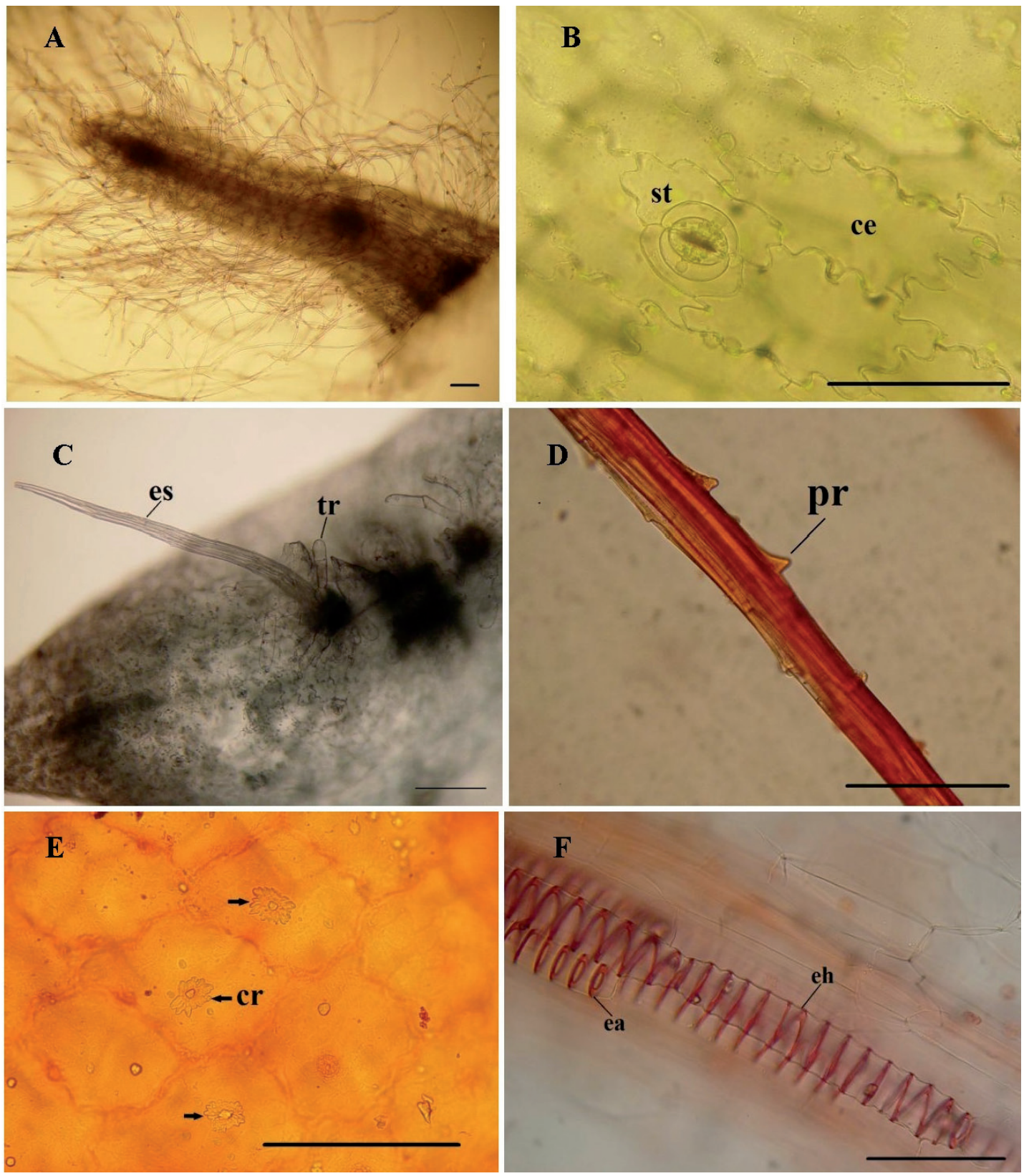

Fig. 4. Trichocereus candicans, A: Raíz con pelos radicales en toda la superficie. B: Células epidérmicas con paredes anticlinales onduladas y estoma paralelocítico, C: areolas con tricomas y espinas. D: Espina con proyecciones. E: Células epidérmicas con cristales. F: Elementos xilemáticos (A-D: plántulas de una semana, E-F: plántulas de 12 semanas). Referencias, st: estoma con células anexas, ce: célula epidérmica con contorno ondulado, es: espina, tr: tricoma, pr: proyecciones, cr: cristales, ea: elementos anillados, eh: elementos helicoidales. Escala: 0,1 $\mathrm{mm}$.

En las primeras cuatro semanas de vida de las plántulas de $T$. candicans ocurren los mayores cambios morfológicos en el eje hipocótilo- cotiledones. Se produce la aparición de las primeras areolas con tricomas y espinas, y se ensancha el epicótilo hasta hacerse visible macroscópicamente. 
La transición a la forma cilíndrica con costillas característica de la especie ocurre a partir de los 12 meses de edad. El momento en que se produce este importante cambio morfológico coincide con lo descripto por Loza-Cornejo y Terrazas (2011) para varias especies columnares de la Tribu Pachycereeae, donde la presencia de las costillas se hace evidente entre los 12-14 a 24 meses. Esta observación demuestra el lento crecimiento de las plántulas aún en condiciones donde el agua no es limitante.

La epidermis de las plántulas de $T$. candicans es uniestrata con cutícula típica de la subfamilia Cactoideae (Gibson \& Nobel, 1986; Terrazas \& Arias, 2003). Las células epidérmicas poseen paredes anticlinales onduladas similares a lo reportado por Loza-Cornejo y colaboradores (2003) en plántulas Stenocereus queretaroensis (F.A.C.Weber ex Mathes.) Buxb. En dicho estudio las células epidérmicas de plántulas y tallos adultos diferían, ya que estos últimos presentan paredes anticlinales rectas y divisiones secundarias. Los estomas son de tipo paralelocítico coincidiendo con lo descripto por Eggli (1984) para otras especies del género Trichocereus. En la epidermis también se distingue la presencia de drusas, siendo estas agrupaciones de cristales de forma estrellada comunes en la subfamilia Cactoideae (Terrazas \& Arias, 2003; BarcenasArgüello, 2011; Secorun \& de Souza, 2011). Numerosos investigadores proponen que los cristales tienen funciones de soporte mecánico, defensa de la plántula ante la herbivoría y además podrían evitar el colapso celular cuando el tejido pierde la suculencia (Gibson \& Nobel, 1986; Terrazas \& Mauseth, 2002; Ayala-Cordero et al., 2006; Barcenas-Argüello, 2011). Se ha propuesto utilizar los cristales para la diferenciación de géneros o especies relacionados, sin embargo no existe consenso aún entre los investigadores respecto a este tema (Gibson \& Nobel, 1986; Terrazas \& Arias, 2003; Tovar-Puente et al., 2007). Sería fundamental realizar más estudios para profundizar en esta temática y, en particular, analizar la presencia, el tipo y la ubicación de los mismos tanto en plántulas como en adultos. Las traqueidas de banda ancha presentes en el xilema son típicas del estadio de plántula de la tribu Trichocereeae y permitirían a las células expandirse y contraerse sin sufrir daños (Mauseth, 2004).

El desarrollo de plántulas con tres cotiledones evidencia la presencia de teratologías (anomalías en el crecimiento) en $T$. candicans. Las dos variantes observadas en el número normal de cotiledones y su disposición también han sido informadas en plántulas de otras dos Cactáceas sudamericanas. Por ejemplo, Secorun y de Souza (2011) describieron plántulas del cactus epífito Lepismium cruciforme con tres cotiledones equidistantes. Por otro lado, García de Almeida y colaboradores (2009) mencionan la presencia de tres cotiledones asimétricos en Cereus hildmannianus. El presente estudio constituiría el primer registro de este tipo para $T$. candicans. Si bien la presencia de tres cotiledones es un fenómeno conocido en varias familias de plantas vasculares, no existe acuerdo entre los investigadores acerca de la causa que lleva a la formación de un tercer cotiledón y la función del mismo durante el desarrollo de la planta (Conner \& Agrawal, 2005; Hu et al., 2005). Estas anomalías podrían ser de interés para profundizar el conocimiento del patrón de desarrollo normal de la plántula.

Este trabajo aporta datos básicos al conocimiento de la especie que pueden ser de gran utilidad para estudios taxonómicos y ecológicos. Por otra parte, para lograr un mayor entendimiento de los cambios morfo-anatómicos observados en las plántulas, debería investigarse la relación de éstos con los procesos fisiológicos que se producen en estadios tempranos del desarrollo.

\section{Agradecimientos}

Los autores agradecen al Área de Ecología de la Facultad de Agronomía-UNLPam. por facilitar las instalaciones, a M. Yicarean por la asistencia técnica en el laboratorio, a la Administración de Parques Nacionales y personal del P.N. Lihue Calel por su colaboración. Agradecemos a los revisores anónimos por sus valiosos comentarios y sugerencias sobre el manuscrito. Este proyecto fue llevado a cabo en la Facultad de AgronomíaUNLPam y se realizó con apoyo financiero de la Facultad de Ciencias Exactas y Naturales-UNLPam y del PRH-PICT 0301 UNLPAM.

\section{Bibliografía}

AYALA-CORDERO, G., T. TERRAZAS, L. LÓPEZMATA \& C. TREJO. 2006. Morpho-anatomical changes and photosynthetic metabolism of Stenocereus 


\section{J. Cenizo et al. - Morfo-anatomía de Trichocereus candicans}

beneckei seedlings under soil water deficit. J. Exp. Bot. 57: 3165-3174.

BARCENAS-ARGÜELLO, M. L. 2011. Distribución ecológica del subgénero Neodawsonia Backeb. Del género Cephalocereus Pfeiff. (Cactaceae) en el Itsmo de Tehuantepec, México. Tesis de Doctorado en Ciencias. Montecillo, Texcoco, Edo. de México.

BOKE, N. H. 1980. Developmental morphology and anatomy in Cactaceae. Bioscience 30: 605-610.

BREGMAN, R. \& F. BOUMAN. 1983. Seed germination in Cactaceae. Bot. J. Linn. Soc. 86: 357-374.

CONNER, J. K. \& A. A. AGRAWAL. 2005. Mechanisms of constraints: the contributions of selection and genetic variance to the maintenance of cotyledon number in wild radish. J. Evolution. Biol. 18: 238-242.

D’AMBROGI DE ARGÜESO, A. 1986. Manual de Técnicas en Histología Vegetal. Ed. Hemisferio Sur, Argentina.

DUBROVSKY, J. G. 1997. Determinate primary-root growth in seedlings of Sonoran Desert Cactaceae; its organization, cellular basis, and ecological significance. Planta 203: 85-92.

DUBROVSKY, J. G. \& G. B. NORTH. 2002. Root structure and function. Pp 41-55. In Nobel, P. S. (ed) Cacti: biology and uses. University of California Press, Los Angeles, USA.

DUBROVSKY, J. G. \& L. F. GÓMEZ-LOMELI. 2003. Water deficit accelerates determinate developmental program of the primary root and does not affect lateral root initiation in a Sonoran Desert cactus (Pachycereus pringlei, Cactaceae). Am. J. Bot. 90: 823-831.

EGGLI, U. 1984. Stomatal types of Cactaceae. P1. Syst. Evol. 146: 197-214.

GARCÍA AGUILAR, M. A., T. TERRAZAS \& S. ARIAS. 2009. Stem anatomy of three species of genus Hylocereus (Berger) Britton \& Rose (Cactaceae) in México. Rev. Fitotec. Mex. 32: 201-208.

GARCÍA DE ALMEIDA, O. J., L. A. DE SOUZA \& I. S. MOSCHETA. 2009. Morfo-anatomía da plântula de indivíduos somaclones de Cereus hildmannianus Schumann (Cactaceae). Bol. Soc. Latin. Carib. Cact. Suc. 6: 29-35.

GIBSON, A. C \& P. S. NOBEL. 1986. The cactus primer. Harvard University Press, Cambridge, Massachusetts.

HERRERA-CÁRDENAS, R., T. TERRAZAS \& S. LOZACORNEJO. 2000. Anatomía comparada del tallo y de la raíz de las especies del genero Neoevansia marshall (Cactaceae). Bol. Soc. Bot. México 67: 5-16.

HU, J., J. F. MILlER, J. CHEN \& B. A. VICK. 2005. Preliminary observation on a spontaneous tricotyledonous mutant in sunflower. Res. Workshop Proc. 27th Sunflower Research Workshop, January 1213, 2005, Fargo, ND.

KIESLING, R. 1978. El género Trichocereus (Cactaceae) Apéndice I: Las especies de la República Argentina.
Darwiniana 21: 263-330.

LOZA-CORNEJO, S. \& T. TERRAZAS. 2003. Epidermal and hypodermal characteristics in North American Cactoideae (Cactaceae). J. Plant Res. 116: 27-35.

LOZA-CORNEJO, S., T. TERRAZAS, L. LÓPEZ-MATA \& C. TREJO. 2003. Características morfo-anatómicas y metabolismo fotosintético en plántulas de Stenocereus queretaroensis (Cactaceae): su significado adaptativo. Interciencia 28: 83-89.

LOZA-CORNEJO, S. \& T. TERRAZAS. 2011. Morfoanatomía de plántulas en especies de Pachycereeae: ¿hasta cuándo son plántulas? Bol. Soc. Bot. Méx. 88: $1-13$.

MAUSETH, J. D. 1978. An investigation of the morphogenetic mechanisms which control the development of zonation in seedling shoot apical meristems. Am. J. Bot. 65: 158-167.

MAUSETH, J. D. 1982a. A morphometric study of the ultrastructure of Echinocereus engelmannii (Cactaceae). V. Comparison with the shoot apical meristems of Trichocereus pachanoi (Cactaceae). Am. J. Bot. 69: 551-555.

MAUSETH, J. D. 1982b. A morphometric study of the ultrastructure of Echinocereus engelmannii (Cactaceae). VII. Homogeneity of zones in the shoot apical meristems. Am. J. Bot. 69: 1527-1529.

MAUSETH, J. D. 2004. Wide-band tracheids are present in almost all species of Cactaceae. J. Plant Res. 117: 69-76.

MAUSETH, J. D. 2006. Structure-function relationships in highly modified shoots of Cactaceae. Ann. Bot. 98: 901-926.

SECORUN, A. C. \& L. A. DE SOUZA. 2011. Morphology and anatomy of Rhipsalis cereuscula, Rhipsalis floccosa subsp. hohenauensis and Lepismium cruciforme (Cactaceae) seedlings. Rev. Mex. Biodiv. 82: 131-143.

TERRAZAS, T. \& J. D. MAUSETH. 2002. Shoot anatomy and morphology. In: P. S. Nobel (ed), Cacti: biology and uses, pp. 23-40. University of California Press. Berkeley, California.

TERRAZAS, T. \& S. ARIAS. 2003. Comparative stem anatomy in the subfamily Cactoideae. Bot. Rev. 68: 444-473.

TERRAZAS, T., S. LOZA-CORNEJO \& H. J. ARREOLANAVA. 2005. Anatomía caulinar de las especies del género Stenocereus (Cactaceae). Acta Bot. Venez. 28: 321-336.

TOVAR-PUENTE, A., M. PANDO-MORENO, H. GONZÁLEZ-RODRÍGUEZ, L. SCOTT-MORALES \& S. D. J. MÉNDEZ-GALLEGOS. 2007. Densidad de cristales de oxalato de calcio en quince cultivares de nopal. J. Prof. Assoc. Cactus 9: 91-98.

Recibido el 6 de noviembre de 2012, aceptado 29 de abril de 2013 
